ever the patient's history, signs, or symptoms. The AutoAnalyzer, invented by a clinical chemist, Dr. L. Skeggs, of Cleveland, Ohio ("probably the most significant event which ever occurred in clinical chemistry"), has now been joined by the computer to mark the next era of clinical chemistry, on whose threshold we stand, according to Whitehead. That is the profile era. Experience with profile analysis at Birmingham quickly showed up the defects of so-called normal values with which to compare the data derived from patients. Half the patients in the Queen Elizabeth Hospital are aged over 55 , whereas probing into the sources of normal values showed that they had often been obtained from young people such as medical students. Incidentally, they rarely included determinations on females.

It is a commonplace of clinical practice that an elaborate battery of tests may show a good deal less than a careful rectal examination. But that is not to condemn them as such, only their misuse. If they can indeed be made quickly and economically available for general practitioners, should not a nation-wide scheme for their application be thoroughly studied now? Whitehead refers, for instance, to a machine which can do 20,000 blood ureas comfortably in an afternoon. And he and his colleagues ${ }^{2}$ at Birmingham have recently reported that profile analysis carried out on patients in general practice led to a new diagnosis in $16.9 \%$ of patients, many of whom required an alteration in treatment. Few readers can doubt his conclusion that the role of clinical chemistry in the care of patients will continue to increase.

\section{The Surgical Scrub}

Lister included disinfection of the surgeon's hands with a solution of phenol among the details of the antiseptic method. But with the development of asepsis and the use of rubber gloves this practice was dropped, and until fairly recent times the only step taken by surgeons to reduce the numbers of bacteria on their hands and forearms before operation has usually been a scrub with bar soap under running water.

Wearing rubber gloves obviously reduces the risk of contaminating operation wounds, but the discovery by E. A. Devenish and A. A. Miles ${ }^{1}$ of minute holes through which bacteria could escape in over $20 \%$ of the gloves worn by surgeons showed they were not an entirely reliable barrier against contamination of wounds. Moreover, the skin occluded by a rubber glove becomes moist, and moisture of the skin is associated with an increase in the numbers of its bacteria. ${ }^{2} \mathrm{~A}$ six-minute scrub with ordinary soap and water has been shown to cause a reduction of only about $50 \%$ in the estimated natural bacterial flora of the skin. ${ }^{3}$ It came to be accepted that at least

1 Devenish, E. A., and Miles, A. A., Lancet, 1939, 1, 1088

2 Blank, I. H., in Skin Bacteria and their Role in Infection, ed. H. I. Maibach, and G. Hildick-Smith, p. 43. New York, McGraw-Hill, 1965.

3 Price, P. B., Fournal of Infectious Diseases, 1938, 63, 301.

4 Traub, E. F., Newhall, C. A., and Fuller, J. R., Surgery, Gynecology, and Obstetrics, 1944, 79, 205.

Hufnagel, C. A., Walter, C. W., and Howard, R. W'., Surgery, 1948, 23, 753.

6 Lowbury, E. J. L., Lilly, H. A., and Bull, J. P., British Medical Fournal, $1963,1,1251$

Joress, S. M., Annals of Surgery, 1962, 155, 296.

8 Zintel, H. A., Surgical Clinics of North America, 1956, 36, 257.

9 Dineen, P., Surgery, Gynecology, and Obstetrics, 1969, 129, 1181.

10 Lowbury, E. J. L., Lilly, H. A., and Bull, J. P., British Medical fournal, $1964,2,531$.

11 Lowbury, E. J. L., Lilly, H. A., and Bull, J. P., British Medical fournal, $1960,2,1039$. five minutes' scrubbing with soap and water was desirable, and even such a thorough preparation could not be guaranteed to prevent contamination of the operation wound by the surgeon's hands. For other reasons, however, prolonged scrubbing was undesirable; not only did it add an appreciable time to the operating-list, but it could cause small excoriations of the skin, which became infected, thus increasing the hazard which it was meant to reduce.

The introduction of effective antiseptics, and especially of liquid soaps and detergent preparations containing hexachlorophane ${ }^{4-6}$ or iodophors, ${ }^{7} 8$ changed the position radically. But though repeated two-minute hand washings with such preparations were shown to reduce the estimated numbers of bacteria on the skin progressively to as little as $1 \%$ of the initial counts, or even less, the tradition of five to ten minutes' scrub has apparently died hard even when hexachlorophane or iodophor preparations have been used. It might be supposed that more prolonged washing or scrubbing with the antiseptic preparations will increase their effectiveness, but the evidence does not support this view. P. Dineen ${ }^{9}$ has recently shown, in studies on 50 subjects, that ten minutes' scrub with a hexachlorophane detergent cream or with an iodophor (povidone iodine surgical scrub) did not cause a greater reduction in the estimated numbers of bacteria on the hands than was obtained by five minutes' scrub with these agents. E. J. L. Lowbury, H. A. Lilly, and J. P. Bull ${ }^{10}$ found mean reductions of $99 \%$, $95 \%$, and $85 \%$ in bacterial counts of hand washing taken respectively after rinsing for two minutes, one minute, and half a minute with $0.5 \%$ chlorhexidine in $70 \%$ ethyl alcohol. These workers also found that two minutes' rinsing of the hands of six persons with $70 \%$ ethyl alcohol caused a mean reduction of $64 \%$ in bacterial counts; after two further twominute rinses in rapid succession with $70 \%$ ethyl alcohol the mean reductions in bacterial counts, compared with the counts obtained before the first rinse, were $83 \%$ and $85 \%$ respectively. It was concluded that most of the disinfection occurred in the first two minutes and little further disinfection occurred after four minutes, probably because the bacteria still present on the skin after that time were beyond reach of the antiseptic. On the other hand disinfectant rinses or ablutions repeated at intervals of several hours led to a progressive reduction in bacterial counts to very low equilibrium levels. ${ }^{6}$

The hazard of infection from the hands at operation is sporadic, depending on contamination of a susceptible wound when a surgeon who happens to carry virulent staphylococci wears gloves that happen to become perforated during use. Since this contingency cannot be foreseen, the rational way for the surgeon to meet it is by washing or scrubbing the hands and forearms with an effective antiseptic soap or detergent preparation before every operation. A liquid soap or detergent preparation should be used, because antiseptic bar soaps are less effective. ${ }^{6}$ Since a two-minutes wash with such preparations gives satisfactory disinfection, there is no longer any need for the prolonged ablution which was rational at a time when no antiseptic was used for preoperative cleansing of the hands. Still shorter periods of ablution are likely to be inadequate, because some areas of the skin may then escape the thorough and systematic application of the antiseptic. Though a brush helps to detach dirt and dead epithelial cells, it seems unnecessary to use one for all preoperative ablutions. Two or three minutes' scrubbing (with careful attention to the finger nails) before the first operation and two or three minutes' washing without a brush before the remaining operations of a list should be a reasonable routine for the surgeon. 